
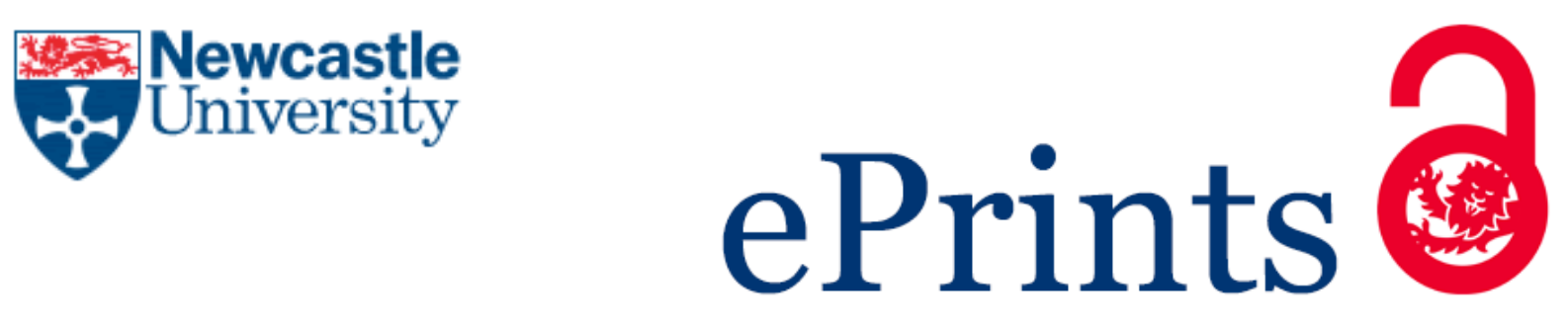

Richards J, Graham R, Embleton ND, Campbell C, Rankin J. Health professionals' perspectives on bereavement following loss from a twin pregnancy: A qualitative study. Journal of Perinatology 2016. DOI: $10.1038 /$ jp. 2016.13

\title{
Copyright:
}

This is the author's accepted manuscript of an article published in its final form by Nature Publishing Group, 2016.

For the terms for reuse for this manuscript please see:

http://www.nature.com/authors/policies/license.html

DOI link to article:

http://dx.doi.org/10.1038/jp.2016.13

Date deposited:

$04 / 03 / 2016$

Embargo release date:

25 August 2016 


\section{Health professionals' perspectives on bereavement following loss from a twin pregnancy: A qualitative study.}

Judy Richards PhD ${ }^{1}$, Ruth H Graham PhD², Nicholas D Embleton MD ${ }^{1,3}$, Judith Rankin PhD ${ }^{1}$.

\section{Affiliations:}

1. Institute of Health \& Society, Newcastle University, Baddiley-Clark Building, Richardson Road, Newcastle upon Tyne NE2 4HH. England.

2. School of Geography, Politics and Sociology, Newcastle University, Newcastle upon Tyne NE1 7RU. England.

3. Newcastle Hospitals NHS Foundation Trust, Newcastle Neonatal Service, Newcastle upon Tyne NE2 4HH. England

Address correspondence to: Professor Judith Rankin. Institute of Health \& Society, Newcastle University, Baddiley-Clark Building, Richardson Road, Newcastle upon Tyne NE2 4HH. England. Email: judith.rankin@ncl.ac.uk .Telephone: 0191 2085267. Fax: 0191 2224567.

Running title: Health professionals' perspectives on twin loss.

This study was funded by the Tiny Lives Trust. Registered Charity Number: 700510. 


\begin{abstract}
Objective: To provide an in-depth understanding of the perspectives of health professionals caring for parents who have lost a baby from a twin pregnancy, either during pregnancy or in the neonatal period.
\end{abstract}

Study Design: A qualitative study involving semi-structured interviews. Twenty-six health professionals were interviewed from maternity and neonatal departments in one hospital. Data were analysed using a generative thematic approach.

Results: Three main themes were identified from the data: health professionals' lack of confidence in their interactions with bereaved parents; their desire to learn more about bereavement; and a consideration of sensitive health care practices for bereaved parents.

Conclusion: Health professionals acknowledged that parents who experience the loss of a twin have specific needs, some of which can be addressed by relatively small changes to clinical practices and behaviours. They felt, however, that they needed education about bereavement in order to react more effectively to bereaved parents' needs.

\title{
Introduction
}

The emotional impact of perinatal loss upon parents has become widely acknowledged ${ }^{1,2}$. There is also an increase in research focussing upon the attitudes, practices, and emotional impact upon the health professionals who care for them ${ }^{3-8}$. The importance of sensitive emotional care from health professionals is well documented as having a significant impact upon life-long memories formed by parents at the time of the loss of their baby ${ }^{9}$. The American Congress of Obstetricians and Gynaecologists guidelines urge sensitivity to the emotional state of the bereaved family ${ }^{10}$, whilst the UK National Institute for Health and Care Excellence guidelines ${ }^{11}$ recommend an increase in psychological support for parents with a high risk pregnancy. 
There are fewer studies that focus specifically upon loss from a twin pregnancy. Those that do recognise the complexity of the loss but lack an in-depth qualitative analysis of the issues involved $^{12-18}$. The challenges of dealing with the complexity of the parents' loss however, are acknowledged, 'whilst reflection is part of best practice and improving care, when reflection involves dealing with birth and death at the same time, the challenge can be immense. ${ }^{19}$ Existing research into the practices and attitudes of health professionals tends to be largely from the accounts of parents ${ }^{20}$. We undertook an in-depth qualitative study which explored the experiences of mothers who had lost a twin and also the health professionals who cared for them across a variety of clinical roles. Our previous paper from this study which focussed upon mothers' perspectives, reported that mothers valued very highly those health professionals who showed sensitivity to their loss, preserved the twin identity of the survivor and gave them time and space to talk about their deceased twin ${ }^{21}$. This paper reports the findings on health professionals' perspectives on caring for parents following a loss from a twin pregnancy.

\section{Materials, Subjects and Methods}

Participants were recruited from both a Neonatal Intensive Care Unit (NICU) and Fetal Medicine Department of a tertiary hospital in the North of England, UK. The centre is recognised as specialising in twin births and there is a dedicated specialist twin's midwife who supports parents with a twin or higher order pregnancy until the babies are born. The services of a social worker, a bereavement counsellor and a psychologist are also available at the centre.

Based on the data from the Northern Survey of Twin and Multiple Pregnancy, at the time of interviewing, about 540 annual twin pregnancies were recorded in women resident in the North of England and among them, about 140 twin pregnancies were delivered in the tertiary 
hospital, of which about 15 pregnancies resulted in a death of one twin (either during

pregnancy or in the first year of life) ${ }^{22}$.

Our sample consisted of 26 health professionals from different disciplines who had cared for parents experiencing a loss from a twin pregnancy (including loss in utero, at birth or in the neonatal period). Purposive sampling was used in order to ensure that the participant group reflected diversity of possible experiences rather than a statistically representative sample ${ }^{23}$.

Prior to interview, written informed consent was obtained. The sample included: six midwives; six neonatal nurses; three neonatal nursery nurses; seven physicians (training grades and substantive appointments); and four allied health professionals. Recruitment continued until theoretical saturation was reached, that is when no more significant themes were emerging from the data ${ }^{24}$.

\section{Interviews}

Semi-structured qualitative interviews were carried out with health professionals in a location convenient to them. The interview topic guide was generative in nature in that the questions provoked discussion rather than prompting definitive answers. The guide also provided flexibility, allowing participant's space to define issues that they regarded as significant, and to articulate their experiences in their own words.

\section{Data analysis}

The data were analysed using a generative thematic approach, which enables the production of an ordered collective picture of rich data. ${ }^{24}$ The interview transcripts were analysed by two non-clinical research team members (JRi and RG) to ensure standardisation of thematic coding. Significant themes were extracted from the data. The research drew on some of the 
principles associated with grounded theory, such as the data-led nature of the analysis, and the constant comparison approach to refining the coding of the data ${ }^{24}$.

\section{Governance}

A favourable ethics approval was received from the County Durham and Tees Valley Research Ethics Committee (Reference: 11.NE.0058.)

\section{Results}

Three overarching themes were identified from the data: Theme 1 focusses upon the management of daily conversations with bereaved parents in the clinical environment whilst their surviving baby is being cared for; Theme 2 highlights the perceived need of staff to understand and learn more about bereavement and trauma; and Theme 3 focusses upon how the perceived needs of bereaved parents can be accommodated within clinical practices which show sensitivity to their loss.

\section{Daily interactions with bereaved parents}

In contrast to provision of care for a singleton loss, many health professionals have regular and prolonged contact with parents following a loss of one or more babies from a twin pregnancy. After bereavement, parents may stay in, or visit, hospital for many weeks with a sick, often premature surviving twin. As a result, their emotional wellbeing at the time of bereavement, and in the weeks/months that follow, becomes part of the caring remit of health professionals. This was commonly identified by health professionals as a fundamental difference between caring for parents with a singleton loss and those who have a loss from a twin pregnancy.

Whilst all health professionals across a range of roles expressed confidence in the medical care surviving twins were receiving, they felt far less confident about addressing the 
emotional needs of grieving parents. Whilst death and bereavement was accepted as, 'an inevitable part of the job' (Midwife), many still felt awkward and unsure about how to manage their daily interactions with parents who had experienced a loss.

\section{i) Acknowledging bereavement}

Nurses often struggled with the issue of when and how to approach the subject of the bereavement with parents. The overwhelming concern was of causing further upset at a time when parents were not only traumatised by the loss of a baby, but also anxious about the likely outcome for the surviving baby. The majority of nursing staff said that they attempted to take the lead from parents themselves as to whether they wanted to talk about their loss. They felt, however, that they were often second guessing parents' emotional needs and felt anxious as to whether they were handling conversations about the loss effectively. Providing information for parents concerning support groups such as TAMBA (Twins and Multiple Births Foundation) or SANDS (Stillbirth and neonatal death charity) was rarely mentioned by nurses on the ward and wasn't recognised as standard practice.

Senior clinical staff often held a more confident view of nurses' ability to deal with bereavement. They acknowledged that certain nursing staff will feel more confident talking to bereaved parents, although many interactions would feel challenging. Finding the time to sit and talk to parents about their bereavement was also raised as an issue by a range of health professionals. On a large NICU, where neonatal death is not uncommon, having multiple conversations with bereaved parents can lead to, 'emotional burnout' for staff.

\section{ii) Maintaining the twin identity of the survivor}

It was suggested by some health professionals that, after the loss of a twin, the clinical emphasis tends to move quickly onto the care of the surviving sibling. This can give parents the impression that the twin identity of the survivor and subsequent parental grief has not 
been adequately recognised. Effective communication with bereaved parents and flexibility of approach was recognised as crucial in order to understand and respond to their emotional needs. It was acknowledged, however, that in contrast to a singleton loss, there could be a tendency to dilute sympathy for parents if there is one or more surviving siblings.

\section{Understanding bereavement and trauma}

Both senior and junior nursing staff expressed a strong desire to gain a deeper understanding of the complex range of emotions that parents who lose a twin are likely to encounter.

\section{i) Complex grieving}

Health professionals across all roles recognised that parents who have lost a twin have complex emotional needs in that they are likely to feel joy and grief simultaneously. Whilst recognising the polarised emotions of bereaved parents, some suggested that it was sometimes easier to try and focus on the positive.

The stage in which parents lose a twin (in utero or in the neonatal period) was perceived to impact upon the emotional care that they received in hospital. A loss in utero may be followed by several more weeks or months of pregnancy. Midwives acknowledged how emotionally challenging it must be to carry a deceased baby for long periods until the babies are delivered, but suggested that health professionals (and often parents themselves) tend to focus upon the development and safe delivery of the surviving twin.

A loss of a live born baby during the neonatal period was often perceived as a more significant bereavement for parents. It was also suggested that the stage of loss will impact upon the complexity of grief in that with a prenatal loss, it was thought by some that parents have had time to grieve for their lost baby before the birth of the surviving baby. 


\section{ii). Education and experience}

Many health professionals, in particular those in more junior roles, expressed a need for formal education about bereavement and trauma, and specialist training in order to understand more clearly the complex rollercoaster of emotions that parents experience when losing a baby from a twin pregnancy. Formal bereavement training and education, however, was not provided internally for staff. It was largely accepted however, that training alone would not provide a universal template for dealing with complex bereavement issues as parents' needs differ, and their needs will change over time. The value of experience was also acknowledged as a way of gaining more confidence and skill when interacting with parents.

The desire for training was partly fuelled by a perceived need to understand more fully how grief can impact upon parents' thoughts and actions whilst they are in hospital. The trauma of losing a baby could impede parents' ability to make decisions in respect of their surviving babies and also increase their anxiety concerning their babies' health. Parents with babies in a NICU environment have the added grief of not always being able to hold and bond with their babies as might happen for a well-baby ${ }^{26}$.

\section{Sensitive care practices}

Alongside emotional support for parents, a number of practical steps were acknowledged which could reassure parents that health professionals were sensitive to their particular circumstances whilst caring for the surviving twin, although the application of these practices was often patchy. These included: remembering and using the name of the deceased baby in conversation with parents; making sure clinical staff practice effective handover and/or read medical notes thoroughly so that they are aware that the baby they are caring for has a deceased sibling; avoiding, where feasible, any significant medical interventions in relation to the surviving twin on the day of the funeral. 
Most health professionals recognised as important the inclusion of the surviving twin in the memory making process by, if possible, taking photographs of the twins together. Also, where possible, attempts were made to keep parents and their surviving twin apart from sets of healthy twins on the ward. Nursing staff, however, suggested that continuity of implementing these practices was often hampered because of insufficient staffing levels, insufficient time, and space constraints.

\section{i) Utilising bereavement services}

There were a range of professionals in the hospital who were able to offer more specialist bereavement support to parents. Nursing staff suggested however, that there was often confusion surrounding when and how to access these services. Given the complex nature of parents' grief, they were unsure when grieving may become viewed as 'unhealthy' and in need of specialist intervention; secondly, they were unsure as to the exact nature of professional support offered, in particular by social workers and clinical psychologists; thirdly, they did not know how to effectively broach the subject of, often stigmatised, counselling support with parents themselves.

Many health professionals felt there should be more information made available to both parents and health professionals as to the remit of each service and how they could be contacted. Many nurses suggested that allied services seem less accessible on the ward. This situation might be improved they suggested, if specialist bereavement professionals visited the ward on an informal and occasional basis, and thereby become more of a familiar face to both parents and staff. Whilst bereavement support to parents after discharge is available, senior physicians found however, that parents often turned down the offer of counselling, citing the reason that it is held too close to the maternity unit where they lost their baby. 
Many health professionals observed the fact that parents who had lost a baby from a twin pregnancy tended to put their grief 'on hold' whilst in hospital. This view raised questions about the effectiveness of bereavement counselling soon after a loss.

Bereavement specialists did recognise that parents may not want to talk in depth about their loss but might appreciate the time away from the ward to talk to someone not involved in their baby's care. Health professionals often referred, however, to an informal 'Buddy' group. This enabled parents sharing similar experiences to be put in touch with each other for mutual support. Health professionals perceived this initiative to be popular with parents.

\section{ii) Communicating information to bereaved parents}

More senior staff in particular, noted that the trauma of the loss of a twin may impact significantly upon the way in which parents receive and interpret information from health professionals in relation to their surviving baby. They stressed the importance of gaining feedback from parents in order to make sure that they have understood the information they have been given. Health professionals across all roles suggested that they reflected upon the ways in which they delivered information in order to be as clear, reassuring and sensitive as possible. A common theme was uncertainty around the possible disparity between how parents appear to be coping on the ward and whether they are revealing the full extent of their emotional distress.

\section{Discussion}

Our study demonstrates that health professionals generally perceive that parents who have experienced a loss from a twin pregnancy do have specific needs, but feel ill-equipped in terms of time, resources and expertise to deal with these challenges. Helping parents deal with the early stages of their grief was recognised as complex as parents may be experiencing 
a range of emotions simultaneously. Additional factors were also recognised as impacting upon grief, including the stage at which the loss occurs.

Conversely, however, it was suggested by some health professionals that there was a tendency to recognise a loss from a twin pregnancy as less significant than a singleton loss. This contradicts evidence from parent studies ${ }^{21,26}$, including our own study, which suggests that the grief for the lost twin is in no way diminished by the presence of the healthy twin.

Health professionals did acknowledge that relatively small practical steps, such as remembering and using the name of the deceased twin for example, can sometimes be taken to improve the experiences of bereaved parents during their time in hospital. Wilson et $\mathrm{al}^{27}$ argue that health professionals who cared for the deceased baby are in a unique position of being able to talk about the deceased twin to parents. We have previously reported that these relatively small steps were very much appreciated by parents ${ }^{21}$. In the context of a large and busy ward, however, consistent implementation of such practices is harder to achieve. Health professionals recognised, for example, that bereaved parents built up relationships of trust with certain staff members during their time in hospital. Due to staffing organisation however, it is not always possible to ensure continuity in the care team of one particular baby.

Professional bereavement support within the hospital was intermittently accessed and often underutilised, mainly due to a lack of understanding as to what services particular roles could offer and when it was appropriate to refer parents. Whilst more junior staff expressed confusion over when to call upon seemingly remote bereavement services, those in more senior roles suggested that financial restraints may prevent more widespread use of such limited services. Whilst improving information availability for both parents and health professionals was seen as a useful way of overcoming some of these issues, there was no consensus on the specific format of such information. 
The intermittent referral of parents to counselling services sits at odds with recommendations that bereavement counselling should always be offered to parents both immediately after their loss and in the long term ${ }^{14}$. Conversely however, McGrath (2011) highlights the fact that studies measuring the effectiveness of counselling soon after neonatal loss are inconclusive and additionally, have not taken into consideration the specific circumstances of loss from a multiple pregnancy ${ }^{28}$. Health professionals in our study observed that parents appeared to put their grief 'on hold' whilst caring for their surviving baby, which calls into question the benefits of counselling at this point. More research is needed to assess the effectiveness of counselling immediately after the loss of a multiple.

Many of the themes that emerged from the data resonate with other qualitative studies. Wallbank and Robertson ${ }^{29}$ found that nurses caring for bereaved parents asked for more bereavement training and felt unprepared to deal with parents' emotional needs. Similarly, McCreight ${ }^{30}$ recognised the pivotal role of nurses in building up a relationship of trust with bereaved parents. Other studies ${ }^{31-33}$ do highlight the specific psychological aspects of loss from a twin or multiple pregnancy upon all family members but lack the in-depth insight of health professionals themselves into what those issues are for parents, what health professionals perceive those needs to be and the disparity between the two.

The study has some limitations. The findings of the study relate to the parameters of the research field set within one hospital, and may not be generalizable to other populations. At this site there was a midwife whose role was dedicated to caring for twin pregnancies which was acknowledged as a very valuable resource for parents. Health professionals' experiences in other settings may reflect differences in resource availability, service quality and other contextual factors. It is important to note however, that even in a site recognised as a centre of excellence for the care of parents experiencing a multiple birth, issues concerning bereavement have been highlighted and require attention. 
By focusing on the experiences of loss from a twin pregnancy, we hope this study will encourage more qualitative research into the specific practical and emotional issues faced by bereaved parents. Issues raised within this study that could warrant further research include: the impact of the trauma of a loss upon decision making for parents whilst in hospital (planning a baby's funeral for example) and the ways in which health professionals can enable bereaved parents to make informed decisions in emotionally challenging times. Further insight will enable health professionals to understand more fully the complex needs of parents who lose a twin in utero, at birth or neonatally and subsequently feel better equipped to provide effective emotional care to bereaved parents during their time in hospital.

\section{Acknowledgements}

The research team would like to thank all the health professionals who took part in this study. We would also like to acknowledge the valuable contributions of Professor Steve Robson, Professor of Fetal Medicine, Jane Denton, CBE (Director of the Multiple Births Foundation and Chair of the project Steering Group), Claire Campbell (Senior nurse In NICU) and Sandra Bosman (Multiples Midwife).

Conflict of interest. The authors declare no conflict of interest. This project was funded by the Tiny Lives Trust. Registered Charity Number: 700510. The funders played no part in the study design, data collection, data analysis, report writing or publication decisions.

Supplementary information is available at the Journal of Perinatology's website 


\section{References}

1. Gold KJ. Navigating care after a baby dies: a systematic review of parent experiences with health providers. J Perinatol 2007; 27: 230-237.

2. Einaudi MA, Le Coz P, Malzac P, Michel F, D’Ercole C, Gire C. Parental experience following perinatal death: exploring the issues to make progress. Eur J Obstet Gynecol Reprod Biol 2010; 151: 143-148.

3. Goëb JL, Leblanc-Deshayes M, Coin L, Malka J, Bouderlique C, Duverger P. Neonatal death of a new-born twin Arch Pediatr 2004; 11: 1135-1138.

4. Roehrs C, Masterson A, Alles R, Witt C, Rutt P. Caring for families with Perinatal Loss. J Obstet Gynecol Neonatal Nurs 2008; 37: 631-639.

5. Chan MF, Lou FL, Cao FL, Ping L, Liu L, Wu LH. Investigating factors associated with nurses' attitudes towards perinatal bereavement care: a study in Shandong and Hong Kong. J Clin Nurs. 2009; 18: 2344-2354.

6. Chan MF, Lou FL, Arthur DJ. Survey Comparing the Attitudes toward Perinatal Bereavement Care of Nurses from Three Asian Cities. Eval Health Prof 2010; 33: 514533.

7. Beck CT, Gable RK. Secondary traumatic stress in labor and delivery nurses: A mixed methods study. J Obstet Gynecol Neonatal Nurs 2012; 41: 747-760.

8. Puia D, Lewis L, Beck C. Experiences of Obstetric Nurses Who Are Present for a Perinatal Loss. J Obstet Gynecol Neonatal Nurs 2013; 42: 321-331.

9. Henley A, Schott J. The death of a baby before, during, or shortly after birth. Good practice from the parents perspectives. Semin Fetal Neonatal Med 2008; 13: 325-328.

10. American Congress of Obstetricians and Gynaecologists. New Guidelines on Managing Stillbirth. 2009. 
11. National Institute for Health and Care Excellence. Multiple pregnancy: The management of twin and triplet pregnancies in the antenatal period 2011. https://www.nice.org.uk/guidance/cg129/chapter/guidance (last accessed 4th August 2015).

12. Bryan EM. The death of a new-born twin: how can support for parents be improved? Acta Genet Stat 1986; 35: 115-118.

13. Bryan EM. The Death of a twin. Palliat Med 1995; 9: 187-192.

14. De Kleine M, Cuisinier M, Kollee L, Bethlehem G, deGraauw K. Guidance after twin and singleton neonatal death. Arch Dis Child 1995; 36: 125-126.

15. Lewis E. Bryan EM. Management of perinatal loss of a twin. BMJ 1988; 19:1321-1323

16. Cleary-Goldman J, D'Alton M. Management of a single fetal demise in a multiple gestation. Am J of Obstet and Gynaecol 2004; 59: 285-298.

17. Swanson PB, Kane RT, Pearsall-Jones JG, Swanson CF, Croft ML. How couples cope with a death of a twin or higher order multiple. Twin Res Hum Genet 2009; 12: 392-402.

18. Knox E, Martin W. Multiples Clinic: a model for antenatal care. Semin Fetal and Neonatal Med. 2010; 15: 357-361.

19. Attia L, Nolan A. Caring for parents following the death of a twin: A student's experience. Brit J Midwif 2011; 19: 665-669.

20. Pector EA, Green J, Ehlers M, Ramsey Carr K, Brink Larsen K, Monaghan O et al. Personal experiences of bereaved twins, parents of twins and their carers. Twin Res 2002; 5: $236-44$.

21. Richards J, Graham RH, Embleton N, Campbell C, Rankin J. Mothers' perspectives on the perinatal loss of a co-twin: A qualitative study. BMC Pregnancy \& Childbirth 2015; 15:143. 
22. Glinianaia SV, Rankin J, Sturgiss SN, Ward Platt MP, Crowder D, Bell R. The North of England Survey of Twin and Multiple Pregnancy. Twin Res Hum Genet 2013; 16: $112-$ 116.

23. Bryman A. Social Research Methods (4th edition). Open University Press. 2012.

24. Pope C, Mays N. Qualitative Research in Health Care. Wiley and Sons. 2007.

25. Braun V and Clarke V. Using Thematic Analysis in psychology. Qual Res in Psych 2006; 3: $77-101$.

26. Cuisinier M, deKleine M, Kollee L, Bethlehem G, deGraaw C. Grief following the loss of a newborn twin compared to a singleton. Acta Paediatr 1996; 85: 339-343

27. Wilson AL, Fenton LJ, Stevens DC, Soule DJ. Death of a Newborn Twin: an Analysis of Parental Bereavement. Pediatrics 1982; 70: 587-591.

28. McGrath JM, Butt, ML, Samra H. Supporting Parents Who Lose a Child of a Multiple Birth: A Critical Review of Research in the Neonatal Intensive Care Unit. New-born Infant Nurs Rev 2011; 11: 203-214.

29. Wallbank S, Robertson N. Midwife and nurse responses to miscarriage, stillbirth and neonatal death: A critical review of qualitative research. Evid Midwif 2008; 6: 100-106.

30. McCreight BS. Perinatal grief and emotional labour: A study of nurses' experiences in gynaecology wards. Int J Nurs Stud. 2005; 42: 439-448.

31. Bryan EM. The impact of multiple preterm births on the family. Int J Obstet Gynaecol 2003; 110: 24-28.

32. Pector EA, Smith-Levitin M. Mourning and psychological issues in multiple birth loss. Semin Neonatol 2002; 7: 247-256.

33. Lewis E and Bryan E. Management of the perinatal loss of a twin. BMJ 1988; 297: 13211322. 